\title{
Article \\ Estimation of the Hot Swap Circulation Current of a Multiple Parallel Lithium Battery System with an Artificial Neural Network Model
}

\author{
Nam-Gyu Lim ${ }^{1}$, Jae-Yeol Kim ${ }^{2}$ and Seongjun Lee ${ }^{2, *}$ \\ 1 Department of Mechanical System and Automotive Engineering, Chosun University, Gwangju 61452, Korea; \\ lnk9100@chosun.kr \\ 2 Department of Mechanical Engineering, Chosun University, Gwangju 61452, Korea; jykim@chosun.ac.kr \\ * Correspondence: 1sj@chosun.ac.kr; Tel.: +82-62-230-7173
}

Citation: Lim, N.-G.; Kim, J.-Y.; Lee, S. Estimation of the Hot Swap Circulation Current of a Multiple Parallel Lithium Battery System with an Artificial Neural Network Model. Electronics 2021, 10, 1448. https:// doi.org/10.3390/electronics10121448

Academic Editors: Mauri Marco and Vincenzo Musolino

Received: 17 May 2021

Accepted: 14 June 2021

Published: 17 June 2021

Publisher's Note: MDPI stays neutral with regard to jurisdictional claims in published maps and institutional affiliations.

Copyright: (c) 2021 by the authors. Licensee MDPI, Basel, Switzerland. This article is an open access article distributed under the terms and conditions of the Creative Commons Attribution (CC BY) license (https:// creativecommons.org/licenses/by/ $4.0 /)$.

\begin{abstract}
Battery applications, such as electric vehicles, electric propulsion ships, and energy storage systems, are developing rapidly, and battery management issues are gaining attention. In this application field, a battery system with a high capacity and high power in which numerous battery cells are connected in series and parallel is used. Therefore, research on a battery management system (BMS) to which various algorithms are applied for efficient use and safe operation of batteries is being conducted. In general, maintenance/replacement of multi-series/multiple parallel battery systems is only possible when there is no load current, or the entire system is shut down. However, if the circulating current generated by the voltage difference between the newly added battery and the existing battery pack is less than the allowable current of the system, the new battery can be connected while the system is running, which is called hot swapping. The circulating current generated during the hot-swap operation is determined by the battery's state of charge (SOC), the parallel configuration of the battery system, temperature, aging, operating point, and differences in the load current. Therefore, since there is a limit to formulating a circulating current that changes in size according to these various conditions, this paper presents a circulating current estimation method, using an artificial neural network (ANN). The ANN model for estimating the hot-swap circulating current is designed for a 1S4P lithium battery pack system, consisting of one series and four parallel cells. The circulating current of the ANN model proposed in this paper is experimentally verified to be able to estimate the actual value within a $6 \%$ error range.
\end{abstract}

Keywords: energy storage system (ESS); hot swap; battery; artificial neural network (ANN); Fitnet; multiple parallel; multiple series; equivalent circuit model (ECM); circulating current

\section{Introduction}

As environmental and resource depletion problems become more serious, research on eco-friendly systems that use batteries, such as electric vehicles, electric-powered ships, and large-capacity energy storage system (ESS) power generation systems that do not use fossil fuels, is accelerating. Since large capacity and high power are required in these fields, battery packs in which numerous battery cells are connected in series/parallel are used. Various studies are being conducted because the role of the battery management system (BMS) is very important to maintain the optimal state of these battery packs and perform protection operations [1-6].

Figure 1 is an example of a large-capacity battery system configuration applied to an energy storage system and an electric propulsion ship. A total of 200 to 300 lithium battery cells are connected in series to form one high-voltage rack, and several racks are connected in parallel to expand the capacity [7]. Hot swap refers to the function of detaching/attaching a module from the DC bus by applying a high voltage relay on the top of the rack for maintenance/replacement of cell unit batteries in the above multiseries/multi-parallel system. At this time, the hot swap action should be performed only 
under certain conditions. The reason is that the difference in the state of charge of the newly added battery and the working battery causes an excessive circulating current.

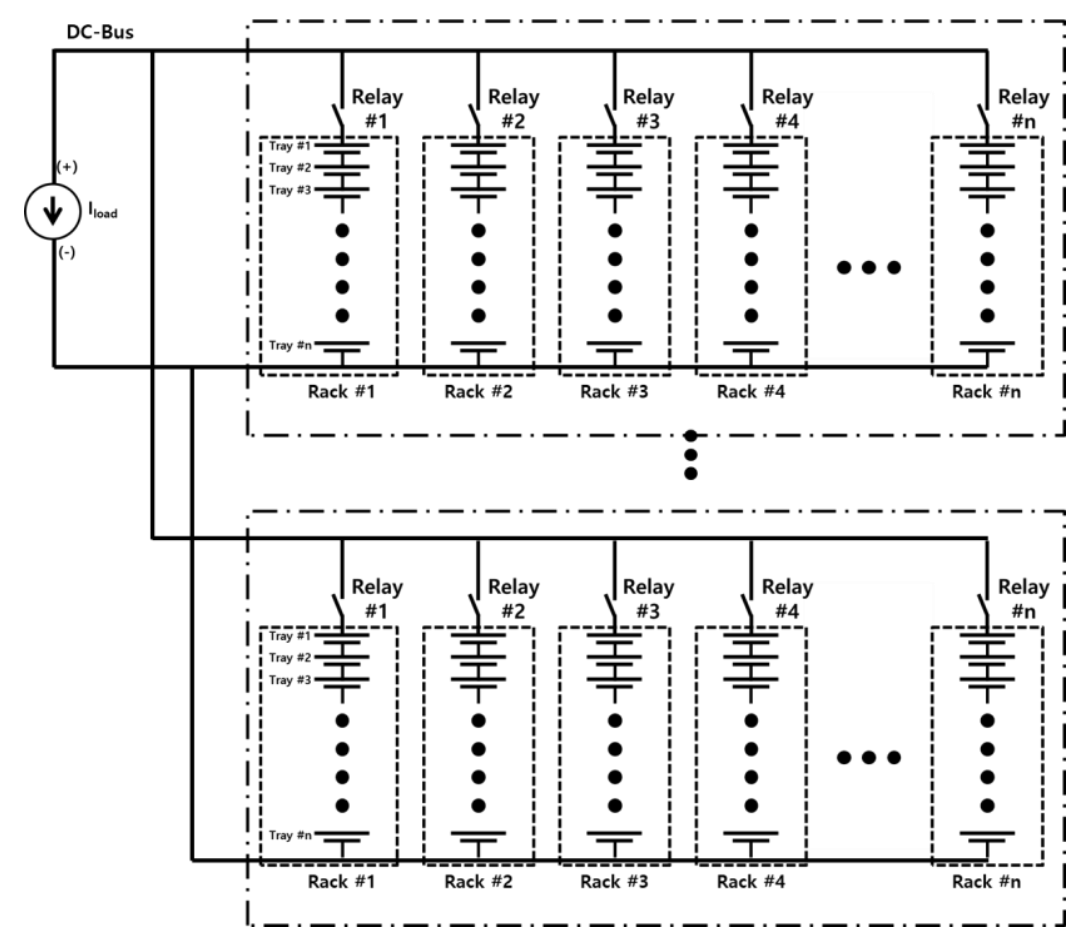

Figure 1. Large-capacity battery system consisting of high voltage modules connected in parallel.

In order to minimize or avoid the circulating current during the hot-swap operation, the hot-swap operation should be performed after matching the state of charge between the newly added battery and the existing working battery. To solve this problem, there was a study on applying a DC/DC converter to match the output voltage of the battery. Jiang et al. used a buck regulator and Moo et al., applied a buck/boost converter to minimize the circulating current by controlling the battery voltage $[8,9]$. These studies devised ways to basically suppress the circulating current caused by the voltage difference of the battery, but they are problematic in that the system size increases and the efficiency decreases when a converter is used to connect the device to a high voltage/power battery system.

On the other hand, studies have been conducted to connect batteries in parallel without using a DC/DC converter. Hsu et al. presented an algorithm for opening and closing switches according to priority through differential classification of SOCs of batteries for both individual and parallel charging of batteries [10]. In this study, an efficient battery parallel connection method without using a DC/DC converter was presented, but the parallel connection condition was simply set as SOC, and only the case where the load current was the charging condition was considered. In addition, studies to estimate the circulating current have not been conducted. Song et al. controlled the switch connected to the battery by using a control algorithm based on fuzzy control logic [11]. They succeeded in lowering the circulating current due to the parallel connection and were able to achieve efficient energy management. In Song's study, similar to that of Hsu, the circulating current was reduced by classifying the battery, according to the SOC, and the circulating current estimation study was not performed. Two previous studies $[10,11]$ used the state of charge (SOC) as a condition for the parallel connection of batteries. Since the state of charge of the battery is an estimated value, there may be an error compared to the actual state of charge. Since the SOC estimation error of parallel-connected battery racks represents a large voltage difference between the battery racks, using only the SOC as a hot swap condition may be problematic. Therefore, in this paper, the terminal voltage of the battery is determined to be a hot-swap condition. 
Lee et al. predicted the circulating current of the battery based on an equivalent model of the battery. To calculate the inrush current that occurs during the hot-swap operation, the equivalent model of the battery is based on the open-circuit voltage and $\mathrm{Ri}$ model. Cell unit tests and the simulation were used to verify the model by applying an EV driving cycle. However, these authors did not verify the situation in which the direction of the charging/discharging load current is changed, nor did they study the characteristics of the battery according to the state change, such as the temperature and aging of the battery [12,13]. Chou et al. conducted a study on the design of a Smart Redundant Battery (SRB) that reflects the direct current internal resistance (DCIR) and pack impedance of the battery (cable, etc.) and the hot-swap conditions that can operate within a set current [14]. Since this study did not consider the hot-swap circulating current, according to the parallel configuration of batteries, it is possible to exceed the current limit of the battery system under the parallel condition of three or more batteries.

In previous studies, various studies on circulating current generation in multi-parallel battery systems were performed, but most studies determined that the circulating current generated during hot-swap operation was due to differences in the SOC of the battery. However, no study was conducted to analyze and estimate the influence of major factors affecting the magnitude of the circulating current generated during hot swapping.

In this paper, the effects of voltage deviation, temperature, parallel configuration, and load current were analyzed as major factors that determine the circulating current generated during a hot-swap operation. After designing a 1S4P battery pack to perform the hot-swap analysis, a 2 RC-based battery equivalent simulation model design was performed. Based on the simulation model, the case study analysis led to hot-swap conditions that could operate within the established current limits. The nD-LUT (Look-Up Table) model can be used to perform a hot-swap operation that reflects various conditions but can only be used as a condition to turn the action on and off. However, the estimated current can be utilized for power management before and after the hot-swap operation as well as determining the hot-swap operation by estimating the circulating current generated during the hot-swap operation.

In the previous study of Lee et al., a formula for calculating the magnitude of circulating current generated during the hot swap was derived from a simplified circuit model of the entire system [13]. The formula for estimating the circulating current can be applied well under the stabilized condition in which the state of charge of the existing connected batteries is the same, but it cannot be used in a situation where the current between the battery cells is unbalanced, due to the continuous hot-swap operation. Therefore, in this paper, an artificial neural network (ANN) model was used to estimate the circulating current generated during the hot-swap operation, considering various conditions in real time.

The ANN model was suggested as a method for estimating the state of the battery, such as the state of charge (SOC) and state of health (SOH) in battery systems but has not yet been applied to studies to estimate the hot-swap circulating current [15-18]. Among the ANN models, the Fitnet model can be fitted to any degree of accuracy if sufficient input values are available. Thus, the results of the simulation-based hot-swap case study analysis were used as the input data, and the circulating current generated under the corresponding condition is displayed as the result [19-21]. Therefore, it is possible to determine the conditions for the hot-swap operation from the results of the circulating current estimation with the ANN model, which can take various conditions into consideration. In this study, an ANN model with two hidden layers was constructed to estimate the hot-swap circulating current of a 1S4P lithium battery pack. The performance of the model in terms of the circulating current estimation was confirmed to be approximately $94 \%$ accurate.

\section{Design of Lithium Battery Model}

The battery system of an ESS consists of numerous battery cells. Specifically, units containing 200-300 lithium battery cells that are connected in series are connected in 
parallel. The battery model for the analysis of the ESS of a cell causes the simulation model to become computationally complex, and the analysis may not be possible. Since a highvoltage battery in a multi-series configuration requires a passive or active cell-balancing function, it can be simplified to a single-cell equivalent model under the assumption that the cell-to-cell voltage is consistent [22].

In this study, the hot-swap analysis was performed, using a scaled down 1S4P lithium battery pack to account for multiple parallel systems.

\subsection{Design of Lithium Battery Equivalent Circuit}

The lithium battery equivalent circuit model (ECM) can be used to describe the nonlinear characteristics of batteries and to estimate the state of the batteries [23-25]. The model can be based on an ECM consisting of voltage sources, resistors, and capacitors as shown in Figure 2. Figure 2a,b shows the first- and second-order RC circuits, respectively. As the number of RCs increases, the accuracy of the model may increase, but the parameters constituting the model increase, which increases the computational intensity and analysis time. In addition, because the nonlinearity of the battery can be sufficiently described with $2 \mathrm{RC}$, the equivalent circuit model was designed using the 2RC model [26]. In this study, the lithium battery equivalent circuit was designed using MATLAB/Simulink software. Two approaches could be followed for the design. First, as shown in Figure 3a, the Simscape or Power Sim library provided by Simulink includes a method for configuring electrical circuit elements. Second, the ECM can be represented by Equation (1), and it can be modeled based on equations using basic blocks as shown in Figure $3 b$.

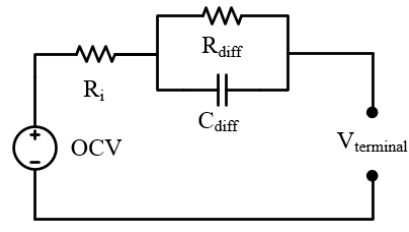

(a)

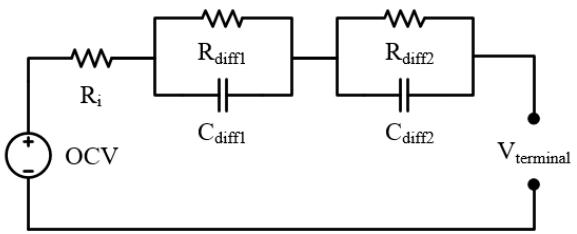

(b)

Figure 2. Battery equivalent circuit model (ECM): (a) 1-RC ECM, (b) 2-RC ECM.

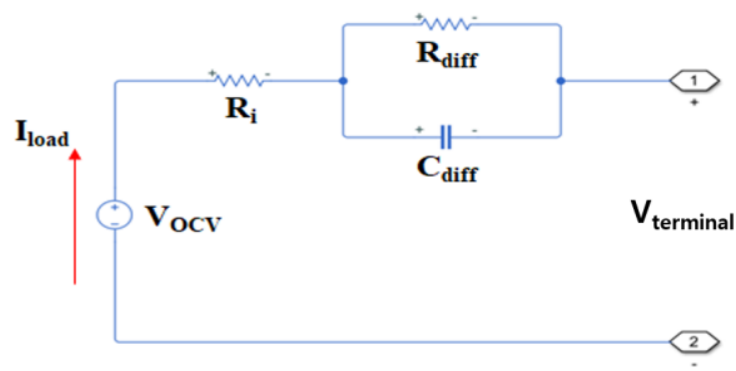

(a)

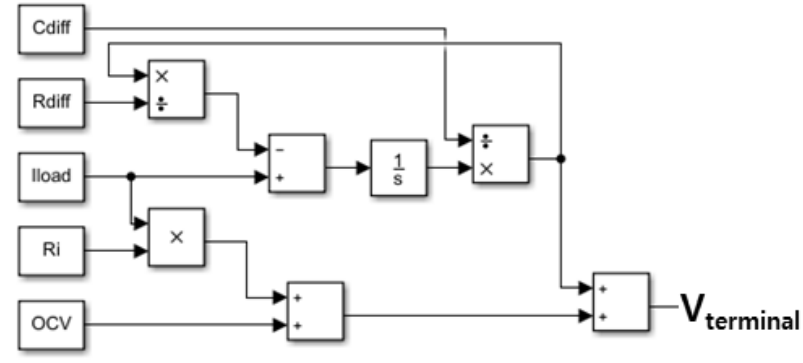

(b)

Figure 3. Modeling the battery ECM by MATLAB/Simulink: (a) modeling using the simscape library; (b) equation-based modeling using basic blocks.

Each parameter constituting the lithium battery equivalent circuit is derived from the voltage characteristic behavior of the current flowing through the lithium battery. In addition, the characteristics of the battery, such as the SOC, temperature, and aging, are not constant and vary with time. Therefore, in this study, a discharge experiment was carried out using battery charging/discharging equipment (Neware, Hong Kong, China, BTS-4000) and a temperature chamber (JEIO Tech, Daejeon, Korea, LCH-11) to reflect the extent to which the characteristics of the battery change, depending on the SOC and temperature in 
the model. The temperature levels were $0,10,23,35$, and $45^{\circ} \mathrm{C}$ and the SOC was tested at $10 \%$ intervals. The experimental profile of the charging/discharging equipment used in the experiment is shown in Figure 4, and the results of the voltage/current measurements in the discharge period are shown in Figure 5 [27].

$$
\mathrm{V}_{\text {terminal }}=\mathrm{OCV}-I_{\text {load }} \times R_{i}-\frac{1}{s}\left(\frac{1}{C_{\text {diff }}}+\frac{V}{R_{\text {diff }} \times C_{\text {diff }}}\right)
$$
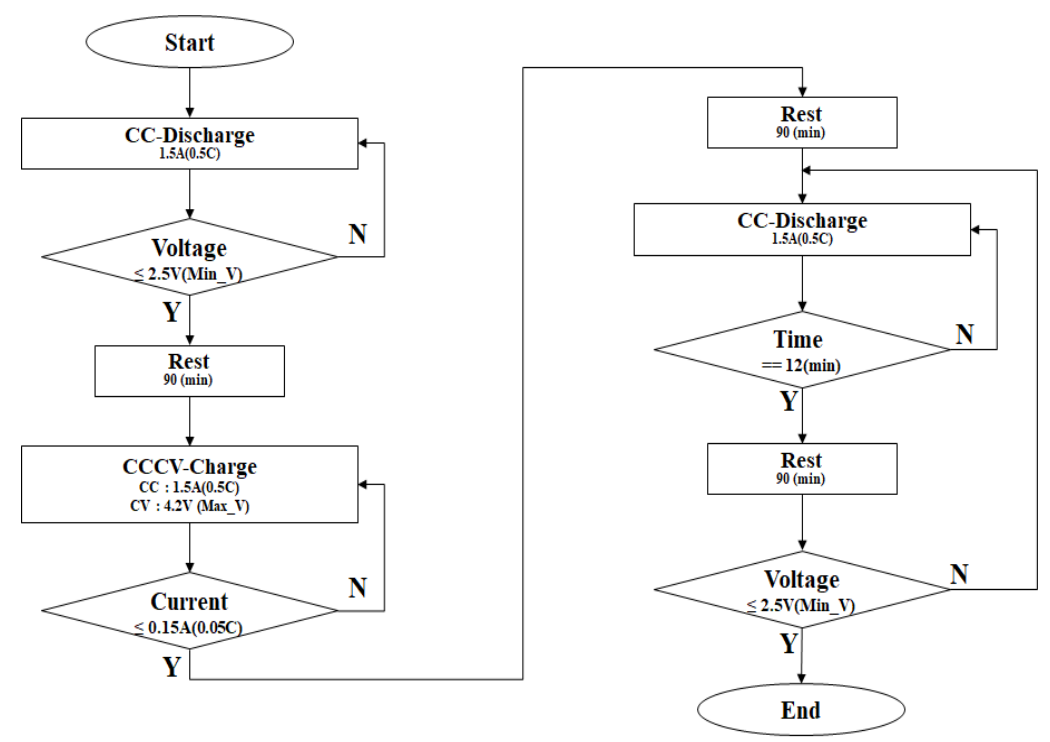

Figure 4. Pulse current discharge test profile.

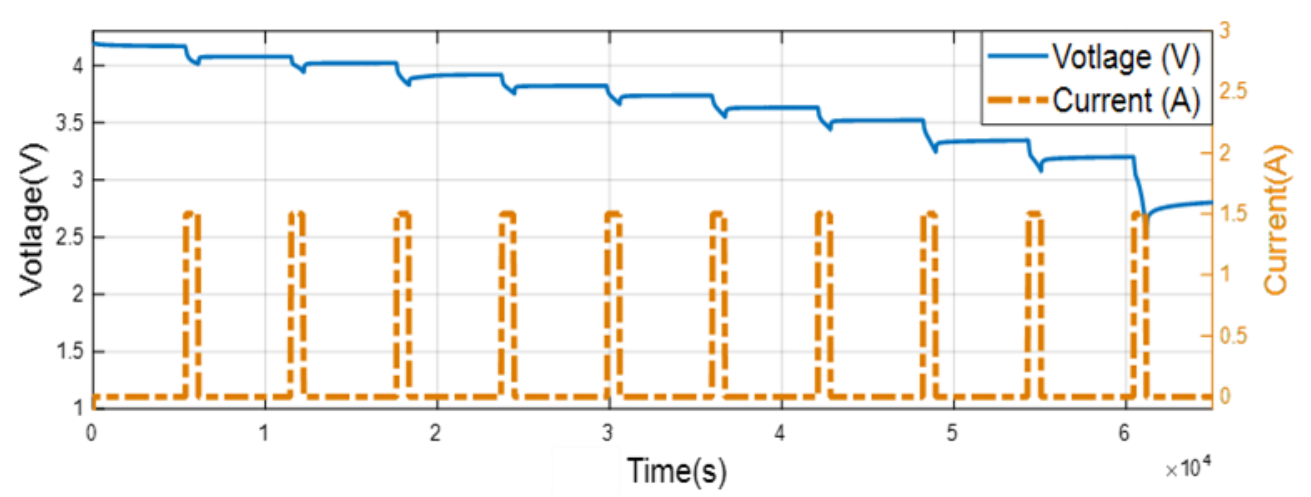

Figure 5. Voltage/current results from pulse current discharge experiment.

The parameters of the equivalent model were derived from the dynamic characteristics of the voltage during the discharge period, and the battery terminal voltage is expressed by Equation (2). The OCV parameter was derived from the voltage in the steady state before the current for each discharge section was applied. The series resistance $R_{i}$ is calculated by dividing the voltage difference denoted as (1) $\Delta V_{1}$, as shown in Figure 6 , by the applied current. The $R_{\text {diff }}$ and $C_{\text {diff }}$ parameters were derived by exponentially fitting the voltage values, excluding the OCV and IR-Drop in (2) $\Delta V_{2}$ in Figure 6. The MATLAB curve-fitting ToolBox was used for function fitting. The fitting was performed by applying Equation (3) to the Custom Equation item of curve-fitting, and the $R_{\text {diff1 }}, R_{\text {diff2 }}$, $C_{\text {diff1 }}$, and $C_{\text {diff2 }}$ parameters were derived from Equations (5) and (6) as a result of the fitting $[28,29]$. Figure 7 shows the results that were obtained using the second-order RC ECM and MATLAB/Simulink/Simscape software, and the parameters derived from the 
above results reflect the characteristics according to the values of SOC and Temp, using the nD-lookup table. To verify the accuracy of the battery ECM model in Figure 7, we performed a terminal voltage comparison between the voltage measurement data of the pulse discharge test and the simulation model. The comparison result is shown in Figure 8, and the ECM model confirmed that the voltage error was less than about $30 \mathrm{mv}$ in most regions except for the low SOC $(<3 \mathrm{~V})$ region, where the nonlinear characteristics of the battery are severe, and the MSE (Mean Square Error) was found to be 0.0011; through this, the accuracy of the single cell ECM model was verified.

$$
\begin{gathered}
V_{t}=\mathrm{OCV}-I_{\text {load }} \times R_{i}-I_{\text {load }} \times R_{\text {diff } 1} e^{\frac{t}{\tau_{1}}}-I_{\text {load }} \times R_{\text {diff } 2 e^{\frac{t}{\tau_{2}}}} \\
\text { Y_fit }=\mathrm{A} \times \exp ^{\frac{-t}{B}}+\mathrm{C} \times \exp \frac{-t}{D} \\
R_{i}=\Delta \mathrm{V} 1 / I_{\text {load }} \\
R_{\text {diff } 1}=\frac{\mathrm{A}}{I_{\text {load }}}, \quad R_{\text {diff } 2}=\frac{\mathrm{C}}{I_{\text {load }}} \\
C_{\text {diff } 1}=\frac{\mathrm{B}}{R_{\text {diff } 1}}, \quad C_{\text {diff } 2}=\frac{\mathrm{D}}{R_{\text {diff } 2}}
\end{gathered}
$$

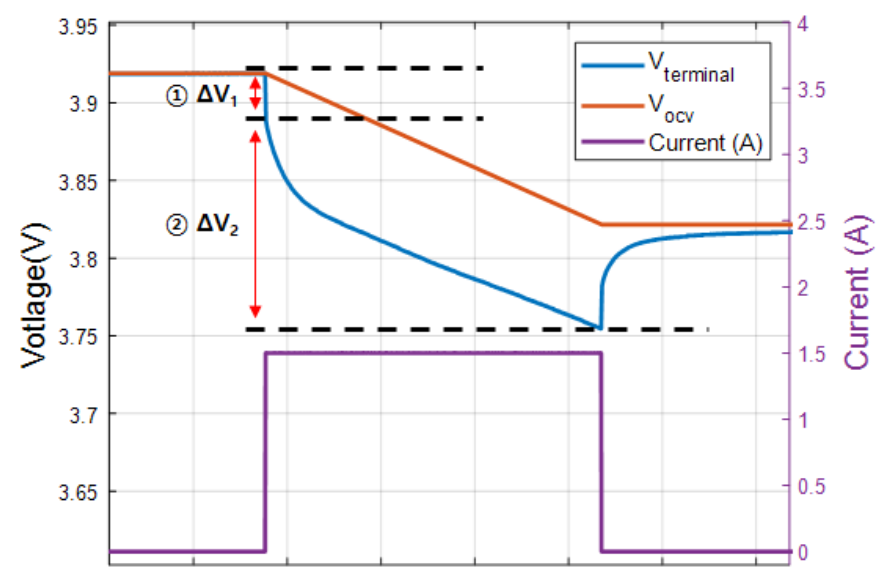

Figure 6. Voltage, OCV, and current waveform when SOC decreased from $70 \%$ to SOC $60 \%$.

\subsection{S4P Lithium Battery Pack Design for Experimental Verification}

To verify the lithium battery software model and the hot-swap experiment, a 1S4P battery pack was designed. Current sensors and relays were allocated for each cell unit to implement the hot-swap function for the parallel connection of batteries in series units of the ESS system. Table 1 lists the components of the lithium battery pack. The INR 18650-30Q was used as the lithium battery, the ACS 712 product with $<5$ A performance was used as the current sensor, and measurements were performed in units of $100 \mathrm{~ms}$, using a myRio-1900 controller. In the case of the voltage measurement, a direct connection was made from the lithium battery to satisfy the analog input specification $(<5 \mathrm{~V})$ of the controller. For the voltage/current measurement and relay control of the lithium battery pack, an experimental set was constructed, using the myRio-1900 controller and LabVIEW software; the composition is shown in Figure 9. 


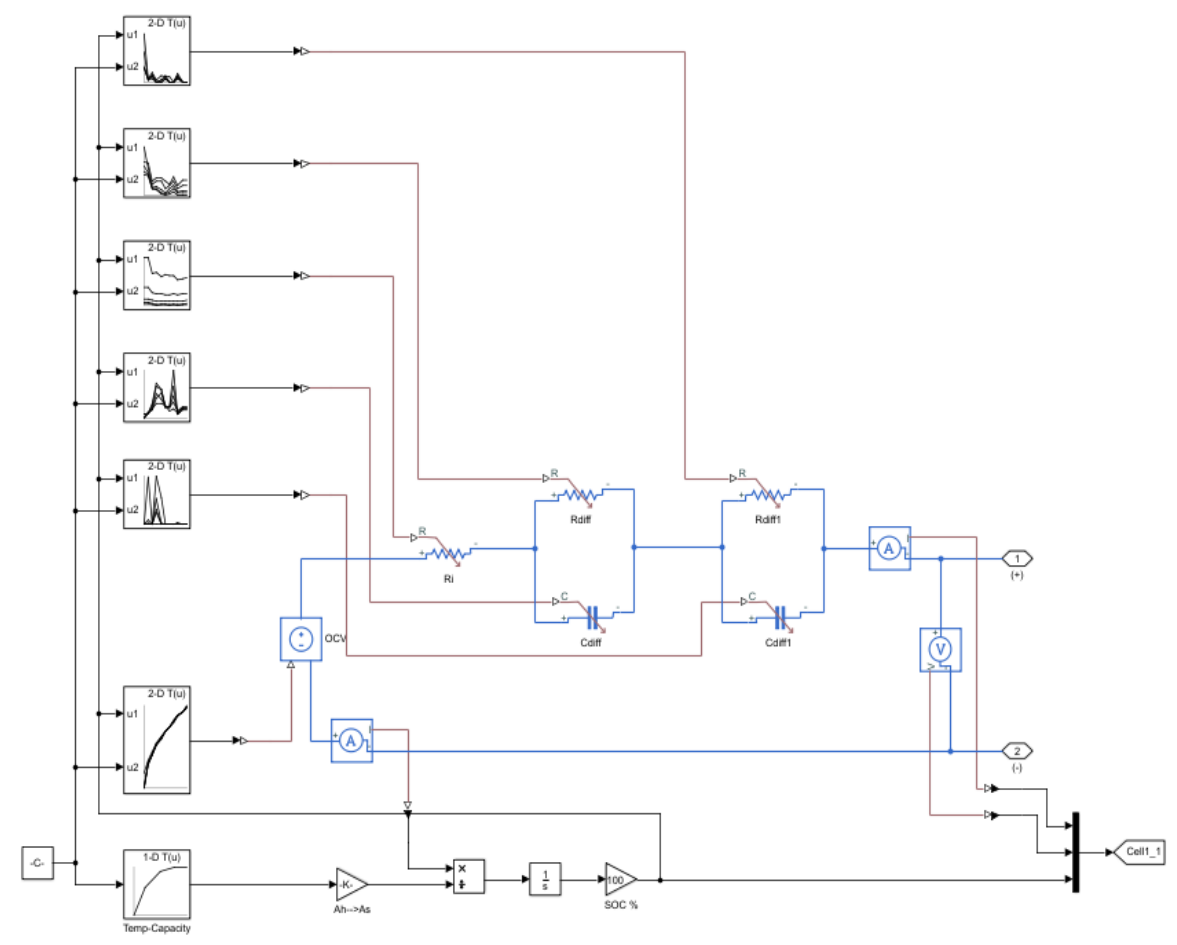

Figure 7. Second-order RC ECM modeling (MATLAB/Simulink/Simscape SW).

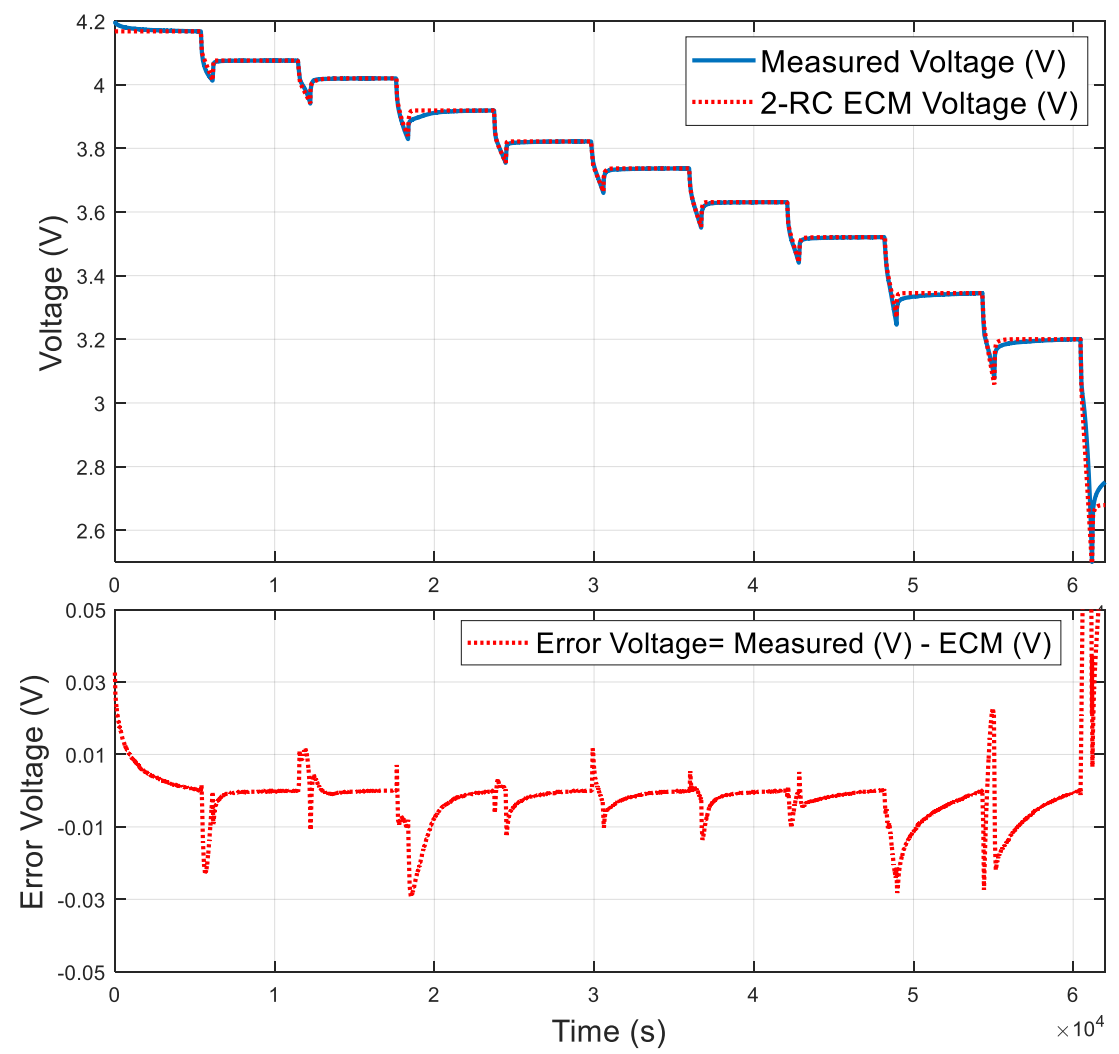

Figure 8. Derived parameter validation simulation results. 
Table 1. Components of 1S4P lithium battery pack.

\begin{tabular}{cc}
\hline Item & Model Name \\
\hline Battery Cell & INR-18650 30Q \\
$(18650$ Type $)$ & $(3040 \mathrm{mAh})$ \\
Relay $(<10 \mathrm{~A})$ & 5 V Relay Module \\
Current Sensor $(<5 \mathrm{~A})$ & (SZH-RLBG-012) \\
Cable & ACS 712 \\
Nickel Plate & $1.5 \mathrm{~mm}^{2}($ cooper $)$ \\
Controller & $5 \mathrm{~mm} / 0.15 \mathrm{~T}$ \\
& NI myRio-1900, \\
Structure & Lab view \\
& 3D Printing \\
\end{tabular}

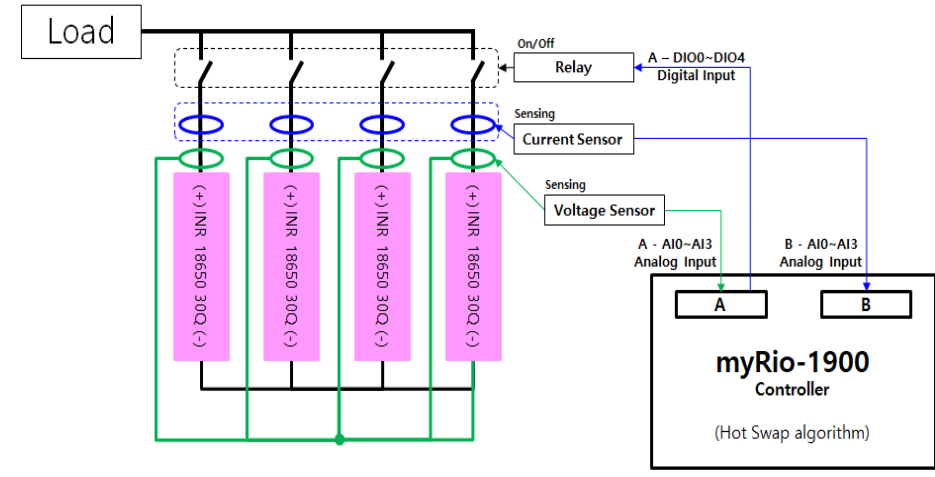

(a)

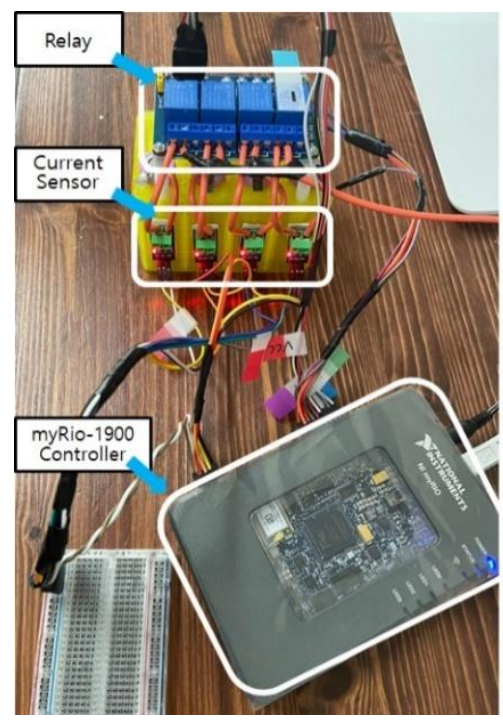

(b)

Figure 9. Configuration of the 1S4P battery pack for the experiment: (a) block diagram of the experimental construction; (b) hot-swap experiment and configuration of the measurement system.

\subsection{Designing Software Model for 1S4P Lithium Battery Pack}

The lithium battery cell model was composed of a second-order RC ECM, as shown in Figure 7, and a relay model was arranged for each cell to implement the relay function, as shown in Figure 10. The relay on-resistor was confirmed experimentally with $30 \mathrm{~m} \Omega$. The cable and contact resistance used in the pack configuration was confirmed by carrying out an experiment with $5 \mathrm{~m} \Omega$, using one resistance model for each cell. The ECM model of the battery pack consisted of a cell model, a relay and other cable resistance models. To verify the accuracy of the modeling, the modeling accuracy was judged by comparing the circulating current generated by performing a hot swap experiment on four batteries with different states of charge. Cell voltage accuracy was performed in Section 2.1. First, as shown in Figure 11, when the $3.932 \mathrm{~V}$ cell and the $3.822 \mathrm{~V}$ cell performed the hot-swap operation, the measured current was $1.02 \mathrm{~A}$ and the ECM simulation result was $1.055 \mathrm{~A}$. Second, when the $3.827 \mathrm{~V}$ and $3.766 \mathrm{~V}$ cells were hot swapped, the measured current was $0.6 \mathrm{~A}$ and the ECM simulation result was $0.585 \mathrm{~A}$. Finally, it was confirmed as shown in Table 2 that the measured current of the $3.766 \mathrm{~V}$ battery and the $3.402 \mathrm{~V}$ battery during the hot-swap operation ws $3.41 \mathrm{~A}$ and the ECM simulation result was $3.54 \mathrm{~A}$. From the above results, it was confirmed that the ECM model of the 1S4P lithium battery pack had an accuracy of $96 \%$ or more. 


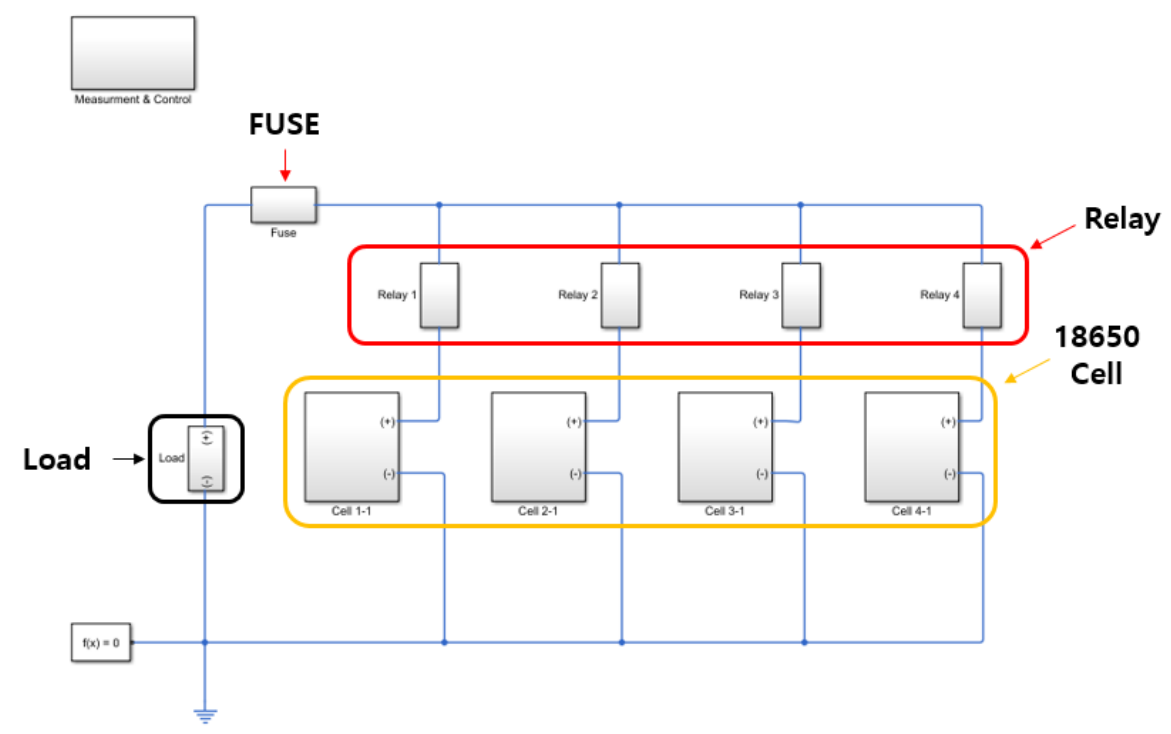

Figure 10. Software model of 1S4P battery pack.

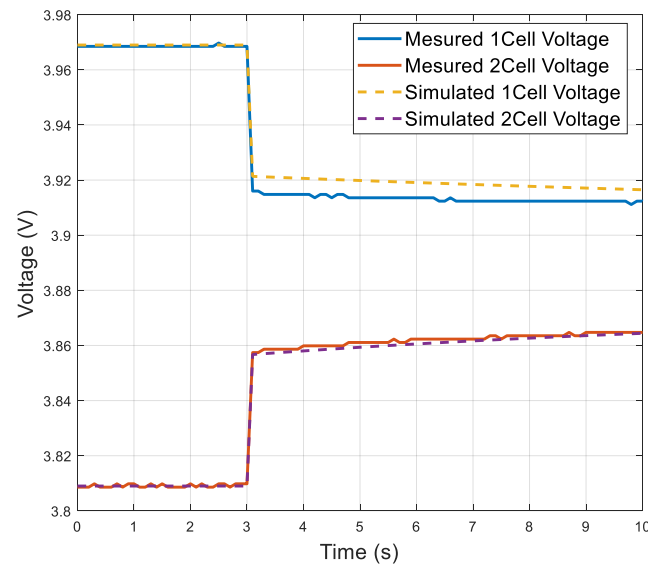

(a)

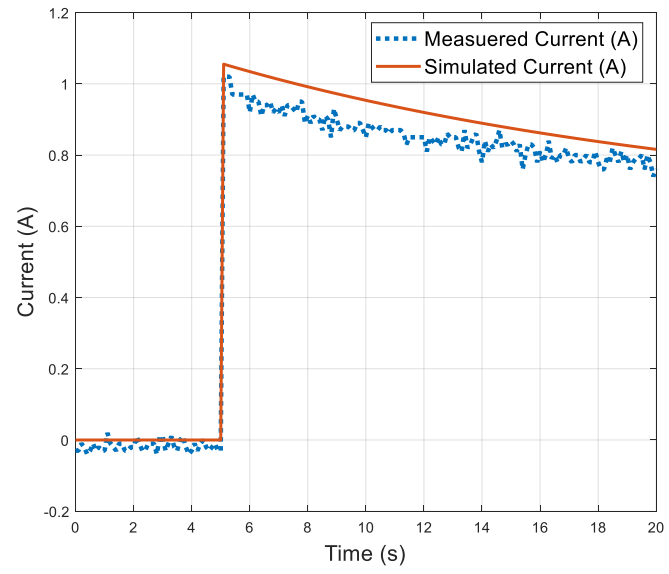

(b)

Figure 11. Comparison of the experimental and simulated results for the hot swap (3.932 V vs. $3.822 \mathrm{~V})$ : experimental and simulated (a) voltage and (b) current.

Table 2. Components of the 1S4P lithium battery pack.

\begin{tabular}{ccccc}
\hline & Cell.N & Voltage & $\begin{array}{c}\text { Measured } \\
\text { (Max. A/Cell) }\end{array}$ & $\begin{array}{c}\text { Simulated } \\
\text { (Max. A/Cell) }\end{array}$ \\
\hline 1 & 1 & $3.932 \mathrm{~V}$ & & $1.055 \mathrm{~A}$ \\
& 2 & $3.822 \mathrm{~V}$ & & $(3.4 \%)$ \\
2 & 2 & $3.827 \mathrm{~V}$ & & $0.585 \mathrm{~A}$ \\
& 3 & $3.766 \mathrm{~V}$ & $0.6 \mathrm{~A}$ & $(2.5 \%)$ \\
& 3 & $3.766 \mathrm{~V}$ & & $3.54 \mathrm{~A}$ \\
& 4 & $3.402 \mathrm{~V}$ & $3.41 \mathrm{~A}$ & $(3.8 \%)$ \\
\hline
\end{tabular}

\section{Hot-Swap Analysis}

The purpose of hot swap analysis is to establish the conditions under which excessive circulating current is not generated when batteries with different charge states are connected in parallel. The magnitude of the circulating current generated during the hot-swap operation is determined not only by the difference in the state of charge of the battery, but also by various factors that determine the characteristics of the battery. Therefore, 
when deriving the conditions for hot swap operation, the optimal hot swap algorithm can be designed by considering the factors that affect the circulating current. In this study, based on the simulation model of the 1S4P configuration, we derived the optimal hot-swap operating conditions by conducting a case study under various conditions.

\subsection{Derivation of Key Factors for Hot Swap (Case Study)}

The key factors that determine the circulating current generated during the hot-swap operation were derived. This was accomplished by analyzing the parallel configuration of the lithium battery packs and hot-swap case studies by varying the temperature, voltage deviation, and load current based on a simulation model of the 1S4P configuration.

\subsubsection{Impact of Parallel Configuration of Battery}

In the 1S4P configuration, the hot-swap parallel configuration in which one battery is inserted is divided into three cases: 1 (On) vs. 1 (Off), 2 (On) vs. 1 (Off), and 3 (On) vs. 1 (Off). Table 3 provides the simulation results with one $4.1 \mathrm{~V}(+0.4 \mathrm{~V})$ or $3.3 \mathrm{~V}(-0.4 \mathrm{~V})$ battery inserted depending on the number of parallel batteries operating under the same conditions $\left(23^{\circ} \mathrm{C}\right.$, load $0 \mathrm{~A}$, voltage $\left.3.7 \mathrm{~V}\right)$. In the case in which $N$ batteries are in operation, it was confirmed that the circulating current is exchanged between $N$ batteries and one battery when one battery with a different charge state is inserted. Therefore, the larger the number of batteries connected in parallel, the greater the circulating current flow in the inserted battery. These results confirmed that it is necessary to reflect the configuration information of the existing connected battery during the hot-swap operation.

Table 3. Effect of battery parallel configuration on hot-swap circulating current.

\begin{tabular}{cccccc}
\hline $\begin{array}{c}\text { Battery } \\
\text { Configuration }\end{array}$ & $\begin{array}{c}\text { X_Cell } \\
\text { Current (A) }\end{array}$ & $\begin{array}{c}\text { Y_Cell } \\
\text { Current (A) }\end{array}$ & $\begin{array}{c}\text { X_Cell } \\
\text { Current (A) }\end{array}$ & $\begin{array}{c}\text { Y_Cell } \\
\text { Current (A) }\end{array}$ \\
\hline 1 vs. 1 & $-3.836 \mathrm{~A}$ & $3.836 \mathrm{~A}$ & $3.732 \mathrm{~A}$ & $-3.732 \mathrm{~A}$ & $\begin{array}{c}\text { X vs. Y } \\
\text { X: Existing_cell }\end{array}$ \\
2 vs. 2 & $-2.555 \mathrm{~A}$ & $5.11 \mathrm{~A}$ & $2.52 \mathrm{~A}$ & $-5.041 \mathrm{~A}$ & $\begin{array}{c}\text { Y: Hot Swap_cell } \\
\text { Load: } 0 \text { A }\end{array}$ \\
3 vs. 3 & $-1.915 \mathrm{~A}$ & $5.746 \mathrm{~A}$ & $1.886 \mathrm{~A}$ & $5.657 \mathrm{~A}$ & Temp: $23^{\circ} \mathrm{C}$ \\
\hline
\end{tabular}

\subsubsection{Effect of Battery Temperature}

Figure 12 shows the results that were obtained by deriving the values of the Figure 12a OCV and Figure $12 b R_{i}$ parameters for each state of charge at each temperature $(0,10,23$, 35 , and $45^{\circ} \mathrm{C}$ ). These results indicated that, as the temperature decreased, the slope of the $\mathrm{OCV}$ decreased and the internal resistance increased. In the absence of a load current and when the $3.7 \mathrm{~V}$ battery is connected in parallel, a circulating current flows through the $3.3 \mathrm{~V}$ inserted battery. The variation in this current with temperature is shown in Figure 13a. The higher the temperature, the larger the magnitude of the circulating current generated under the same conditions. These results confirmed that it is necessary to reflect the temperature information during the hot-swap operation. 


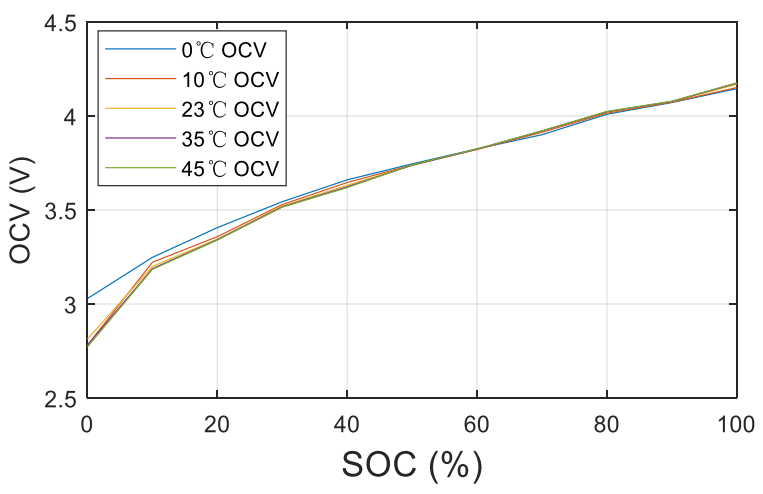

(a)

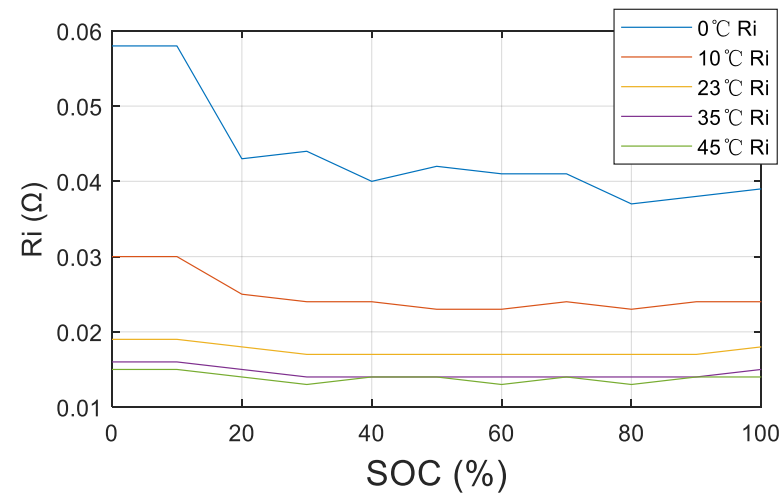

(b)

Figure 12. ECM parameter derivation result by varying SOC temperatures: (a) SOC-OCV; (b) SOC- $\mathrm{R}_{\mathrm{i}}$.

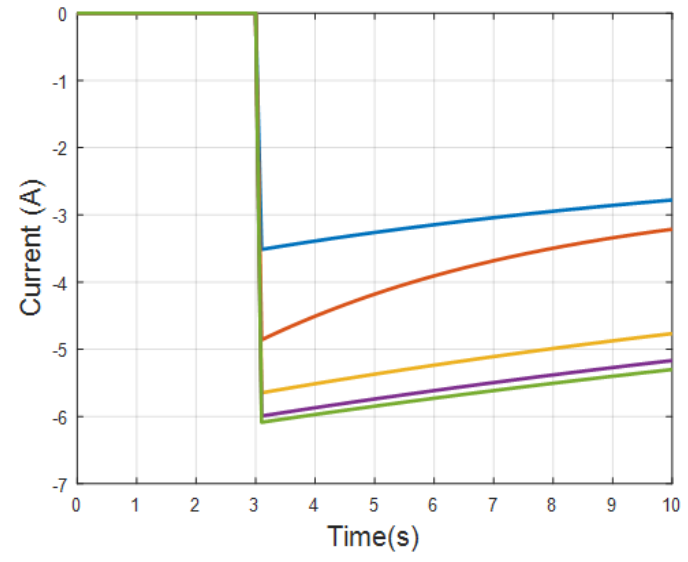

(a)

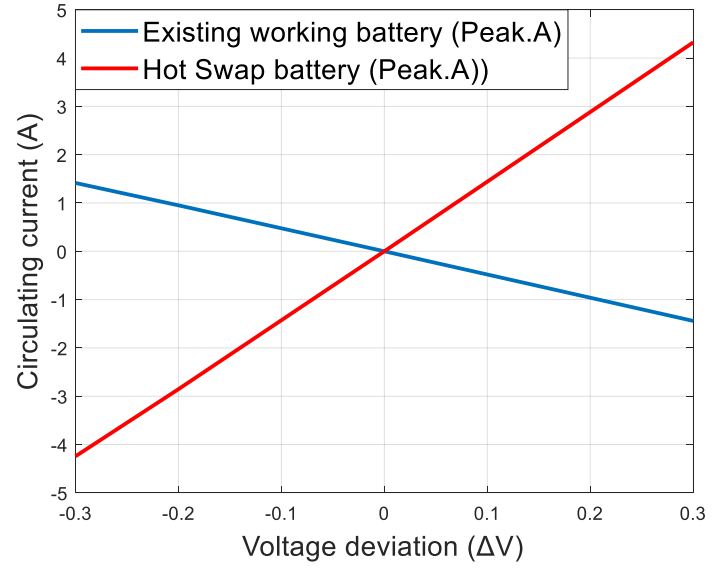

(b)

Figure 13. Influence of battery statements on hot swap circulating current (a) at various temperatures and (b) as a function of the voltage deviation.

\subsubsection{Influence of Deviation in Battery Voltage}

The circulating current generated during the hot-swap operation is generated in the process of maintaining the energy balance from the difference in voltage (SOC) of the battery. Figure $13 \mathrm{~b}$ shows the circulating current that is generated when hot swapping one battery with a voltage deviation of $-0.3 \sim+0.3 \mathrm{~V}$ when three batteries at $23^{\circ} \mathrm{C}$, a load current of $0 \mathrm{~A}$, and $3.7 \mathrm{~V}$ are connected in parallel. The results of the above analysis confirmed that, in the absence of a load current, the circulating current generated during the hot-swap operation under the corresponding condition maintains a linear relationship with the voltage deviation. Therefore, in the absence of a load current, the voltage deviation and circulating current were confirmed to increase and decrease linearly during the hot-swap operation.

\subsubsection{Influence of Load Current}

Figure 14 shows the results of the simulation analysis when a battery with a charge state of $\pm 0.3 \mathrm{~V}$, compared to the terminal voltage, is input when a $3 \mathrm{~A} /$ Cell discharge load current is applied to three batteries connected in parallel with a $3.7 \mathrm{~V}$ charge state. Figure 14a shows the case where a battery of (2) $+0.3 \mathrm{~V}$ is input when a discharge current is applied to the existing connected battery. When the result is changed to charging current (3), a battery with a low existing charging state receives a charging current from the external charging current and the inserted cell. Figure $14 \mathrm{~b}$ shows the case in which a battery of (2) 
$-0.4 \mathrm{~V}$ is inserted when a discharge load current is applied to an existing connected battery. To charge the inserted battery, the existing battery supplies an additional discharge current in addition to the discharge load current. When the load current changes to the charging current at (3), the latter current can confirm the result of the required current concentration needed to charge the inserted battery. This result confirmed that the allowable $(+) /(-)$ voltage deviation range based on the direction of the load current (charge/discharge) is not symmetric. Therefore, it is necessary to reflect the condition of the load current when establishing the hot-swap operation condition.

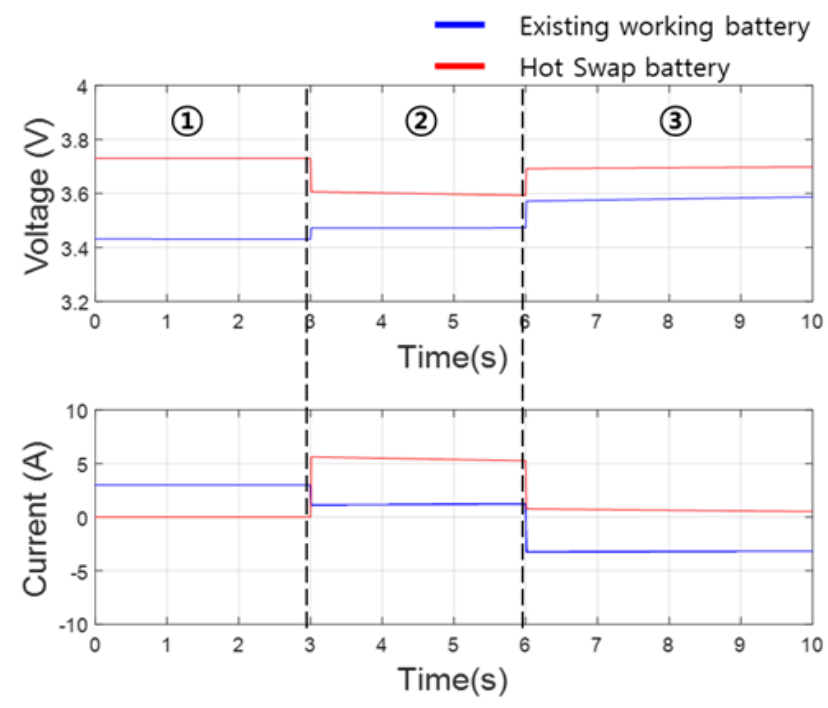

(a)

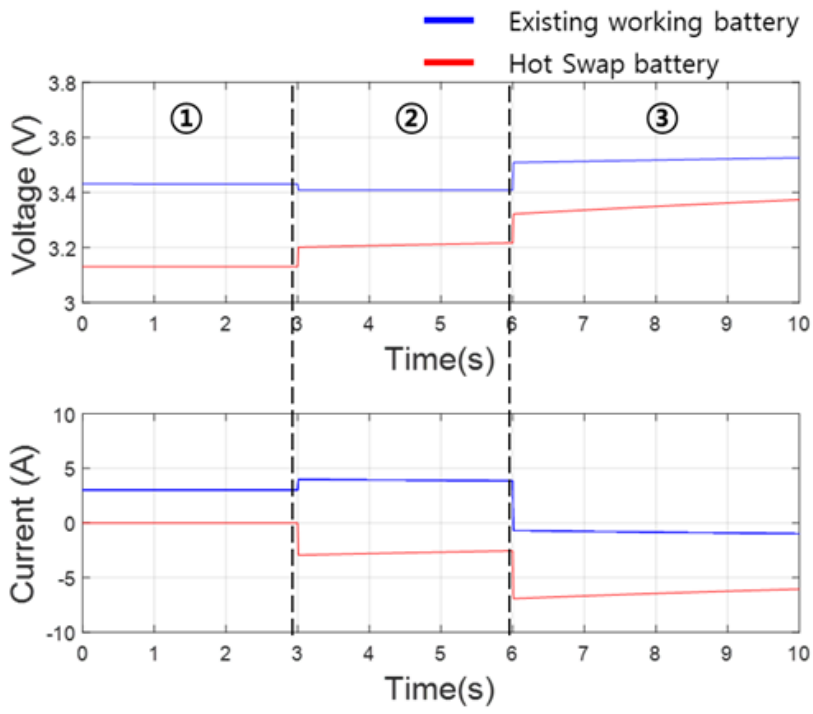

(b)

Figure 14. Simulation results of the hot-swap operation when inserting a battery with $\pm 0.3 \mathrm{~V}$ difference: (a) $+0.3 \mathrm{~V}$ battery hot swap; (b) $-0.3 \mathrm{~V}$ battery hot swap.

\subsection{Derivation of Hot Swap Operating Conditions}

The case study analysis in Section 3.1 enabled a hot-swap condition to be derived in which the magnitude of the circulating current generated during the hot-swap operation in the 3 vs. 1 parallel configuration, which is the worst condition, does not exceed $3 \mathrm{~A} /$ Cell (1C). The factors considered in the hot-swap operation were the load current, temperature, and voltage deviation; the results appear in Table 4. The hot-swap operation can be applied by either using a lookup table as a table or by dividing a specific section by the temperature and load current. However, in the case of a hot-swap operation based on a table, the dimension of the table increases rapidly with the addition of conditions, and the disadvantage is that a look-up table can only be used to turn on/off a simple relay. Therefore, research is needed to estimate the circulating current generated during a hot-swap operation.

Table 4. Hot swap operating voltage conditions for the 1S4P system.

\begin{tabular}{ccccccc}
\hline Mode & $\begin{array}{c}\text { Load } \\
\text { (A/Cell) }\end{array}$ & $\mathbf{0}{ }^{\circ} \mathbf{C}$ & $\mathbf{1 0}{ }^{\circ} \mathbf{C}$ & $\mathbf{2 3}{ }^{\circ} \mathbf{C}$ & $\mathbf{3 5}{ }^{\circ} \mathbf{C}$ & $\mathbf{4 5}{ }^{\circ} \mathbf{C}$ \\
\hline \multirow{3}{*}{ Discharge } & $3 \mathrm{~A}$ & $-0.04-0.23 \mathrm{~V}$ & $-0.01-0.14 \mathrm{~V}$ & $0.01-0.11 \mathrm{~V}$ & $0.00-0.10 \mathrm{~V}$ & $0.00-0.10 \mathrm{~V}$ \\
& $2 \mathrm{~A}$ & $-0.12-0.25 \mathrm{~V}$ & $-0.08-0.17 \mathrm{~V}$ & $-0.06-0.14 \mathrm{~V}$ & $-0.06-0.13 \mathrm{~V}$ & $-0.06-0.13 \mathrm{~V}$ \\
& $1 \mathrm{~A}$ & $-0.23-0.28 \mathrm{~V}$ & $-0.18-0.20 \mathrm{~V}$ & $-0.14-0.17 \mathrm{~V}$ & $-0.14-0.16 \mathrm{~V}$ & $-0.13-0.16 \mathrm{~V}$ \\
\hline \multirow{5}{*}{ Charge } & 0 & $-0.31-0.30 \mathrm{~V}$ & $-0.23-0.23 \mathrm{~V}$ & $-0.20-0.20 \mathrm{~V}$ & $-0.19-0.19 \mathrm{~V}$ & $-0.19-0.19 \mathrm{~V}$ \\
& $1 \mathrm{~A}$ & $-0.28-0.23 \mathrm{~V}$ & $-0.20-0.15 \mathrm{~V}$ & $-0.17-0.13 \mathrm{~V}$ & $-0.16-0.12 \mathrm{~V}$ & $-0.16-0.12 \mathrm{~V}$ \\
& $2 \mathrm{~A}$ & $-0.24-0.05 \mathrm{~V}$ & $-0.17-0.06 \mathrm{~V}$ & $-0.14-0.06 \mathrm{~V}$ & $-0.13-0.06 \mathrm{~V}$ & $-0.13-0.05 \mathrm{~V}$ \\
& $3 \mathrm{~A}$ & -0.21 to $-0.07 \mathrm{~V}$ & -0.14 to $-0.03 \mathrm{~V}$ & -0.11 to $-0.01 \mathrm{~V}$ & -0.10 to $-0.01 \mathrm{~V}$ & -0.10 to $-0.01 \mathrm{~V}$ \\
\hline
\end{tabular}




\section{Artificial Neural Network (ANN) Models}

As mentioned in the discussion of the hot-swap analysis in Section 3, various key factors must be considered to set the hot-swap operating conditions, and a look-up table model can be used to consider various conditions. However, as conditions are added, the dimensions of the table increase and can only be used as simple relay on/off controls. If the circulating current generated during the hot-swap operation can be estimated, hot-swap execution and power management before and after the execution become possible.

\subsection{Design of ANN Model (Fitnet)}

The Fitnet model was used among several ANN models of the deep learning toolbox provided by MathWorks. The Fitnet model can be fitted with any accuracy if there is sufficient input value, as mentioned in the introduction, so it is possible to estimate the circulating current generated during the hot-swap operation with simulation-based input data.

\subsubsection{Inputs and Target Data}

For the input and target data of the Fitnet model, the results of the hot swap case study were used as input; the data type is listed in Table 5. Four conditions (parallel configuration, temperature, load current, and voltage deviation) derived through the case study were set as inputs, and the circulating current generated under the corresponding condition and the current when the load current was reversed were set as target data. For the input and target data of the Fitnet model, the results of the hot-swap case study were used as input; the data type is provided in Table 5. Four conditions (parallel configuration, temperature, load current, and voltage deviation) derived through the case study were set as inputs, and the circulating current generated under the corresponding condition and the current when the load current was reversed were set as target data. There was a total of 500 input data values; $70 \%$ of the input data were randomly classified as train_set, $15 \%$ as validation_set, and the remaining $15 \%$ as test_set, after which the training proceeded.

Table 5. Inputs, targets, and data type of the ANN.

\begin{tabular}{cccc}
\hline Input Parameters & Unit of Measure & Target Parameters & Unit of Measure \\
\hline Parallel State & $\mathrm{N}(1,2,3)$ & Existing_BAT & A/cell \\
$($ Ex, $2=2$ vs. 1$)$ & ${ }^{\circ} \mathrm{C}$ & Hot_Swap_BAT & A/cell \\
Temperature & $\mathrm{A} /$ cell & Existing_BAT & A/cell \\
Load Current & $\mathrm{V}$ & Hot_Swap_BAT & A/cell \\
Deviation Voltage & &
\end{tabular}

\subsubsection{Structure of ANN Model: Hidden Layers and Neurons}

As shown in Figure 15, the performance of the ANN model is determined by the hidden layers, neurons, and training functions that exist between the inputs and outputs. As the number of hidden layers and neurons increases, the accuracy of the model may increase, but this increases the learning time, and the overfitting problem occurs. Therefore, the number of hidden layers and neurons was varied, and the results are provided in Table 6. The results indicate that when two hidden layers with 10 neurons in each layer are used, the model design is optimized. 


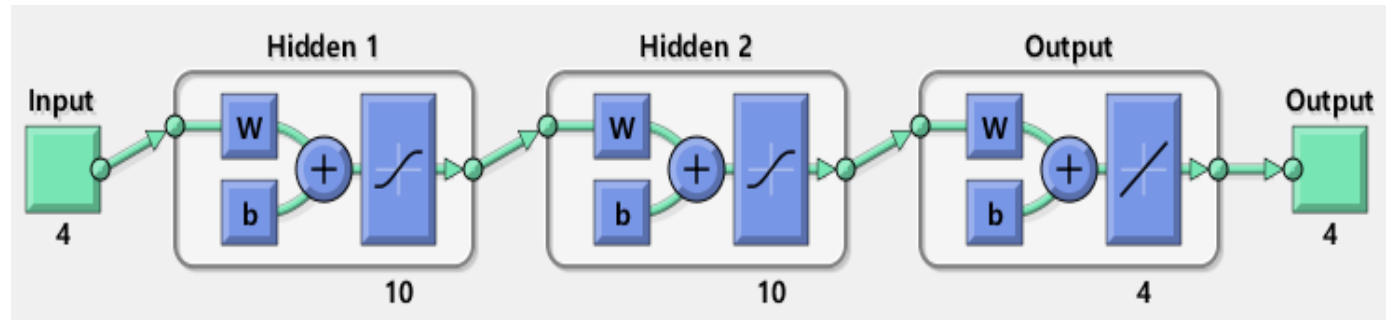

Figure 15. Composition of the artificial neural network model [20].

Table 6. Accuracy of the ANN ${ }^{1}$ depending on the number of hidden layers and neurons.

\begin{tabular}{cccc}
\hline Hidden Layer & Neurons & MSE $^{2}$ & MAE $^{\mathbf{3}}$ \\
\hline 1 & 5 & 0.02520 & 0.1246 \\
1 & 10 & 0.00070 & 0.0177 \\
1 & 15 & 0.00040 & 0.0138 \\
2 & 55 & 0.00170 & 0.0274 \\
2 & 510 & 0.00010 & 0.0096 \\
2 & 105 & 0.00008 & 0.0071 \\
2 & 1010 & 0.00005 & 0.0055 \\
2 & 1515 & 0.00002 & 0.0027 \\
3 & 555 & 0.00097 & 0.0196 \\
3 & 5510 & 0.00067 & 0.0167 \\
3 & 51010 & 0.00006 & 0.0058 \\
3 & 5105 & 0.00110 & 0.0238 \\
3 & 10105 & 0.00200 & 0.0329 \\
3 & 101010 & 0.00002 & 0.0035 \\
\hline
\end{tabular}

${ }^{1}$ Training function: Levenberg-Marquardt, train_set $70 \%$, validation_set $15 \%$, test_set $15 \%,{ }^{2}$ mean square error ${ }^{3}$ mean absolute error.

\subsubsection{Training Function}

The process that was followed to determine the number of hidden layers and neurons for the ANN model is described in Section 4.1.2. In this section, the training functions are compared to determine the most suitable function. The deep learning toolbox provided by MathWorks provides approximately 12 training functions. The model was configured by using each function under the same conditions, which enabled the performance of the model for each function to be confirmed (Table 7). In this model, which is designed to estimate the circulating current from the results in Table 7, the trainlm function applied with the Levenberg-Marquardt algorithm and the trainbr function applied with the Bayesian regularization algorithm delivered superior estimation performance, compared with the other training functions. Of these two functions, the trainlm function was significantly faster than the trainbr function; therefore, the trainlm function was used in the ANN model [30].

\subsection{Validation of ANN Model}

The learned ANN model was validated on the basis of the hot-swap simulation results and hot-swap experimental results obtained for the 1S4P battery packs.

\subsubsection{Simulation-Based ANN Model Validation}

In the 3 vs. 1 configuration, the charging state of the three cells that are already connected is $3.7 \mathrm{~V}$, and the circulating current is generated when a battery with a load current of $-1 \mathrm{~A} /$ Cell and a battery with $+0.13 \mathrm{~V}$, compared to the terminal voltage, are input. The direction of the load current changes after $3 \mathrm{~s}$. The flowing load current was compared with the simulation model. The results obtained using the following input values for the ANN model are shown in Figure 16: module configuration 3, temperature $\left(23^{\circ} \mathrm{C}\right)$, load current $-1 \mathrm{~A} / \mathrm{Cell}$, and voltage deviation $0.13 \mathrm{~V}$. As a result of comparing 
the simulation results in Table 8 with the ANN model, it can be seen that the circulating current estimation performance of the ANN model operated around 3\%.

Table 7. Results of performance analysis of model according to training function.

\begin{tabular}{cccc}
\hline Training Function & Algorithm & MSE & MAE \\
\hline trainlm & Levenberg-Marquardt & 0.00006 & 0.0055 \\
trainbr & Bayesian Regularization & 0.00003 & 0.0038 \\
trainbfg & BFGS Quasi-Newton & 0.0023 & 0.0358 \\
trainrp & Resilient Backpropagation & 0.0139 & 0.0898 \\
trainscg & Scaled Conjugate Gradient & 0.0088 & 0.0702 \\
traincgb & Conjugate Gradient with Powell/Beale Restarts & 0.0094 & 0.0738 \\
traincgf & Fletcher-Powell Conjugate Gradient & 0.0314 & 0.1376 \\
traincgp & Polak-Ribiére Conjugate Gradient & 0.0272 & 0.1262 \\
trainoss & One-Step Secant & 0.0322 & 0.1416 \\
traingdx & Variable Learning Rate Gradient Descent & 0.2575 & 0.4019 \\
traingdm & Gradient Descent with Momentum & 35.2494 & 4.9497 \\
traingd & Gradient Descent & 0.2088 & 0.3584 \\
\hline
\end{tabular}
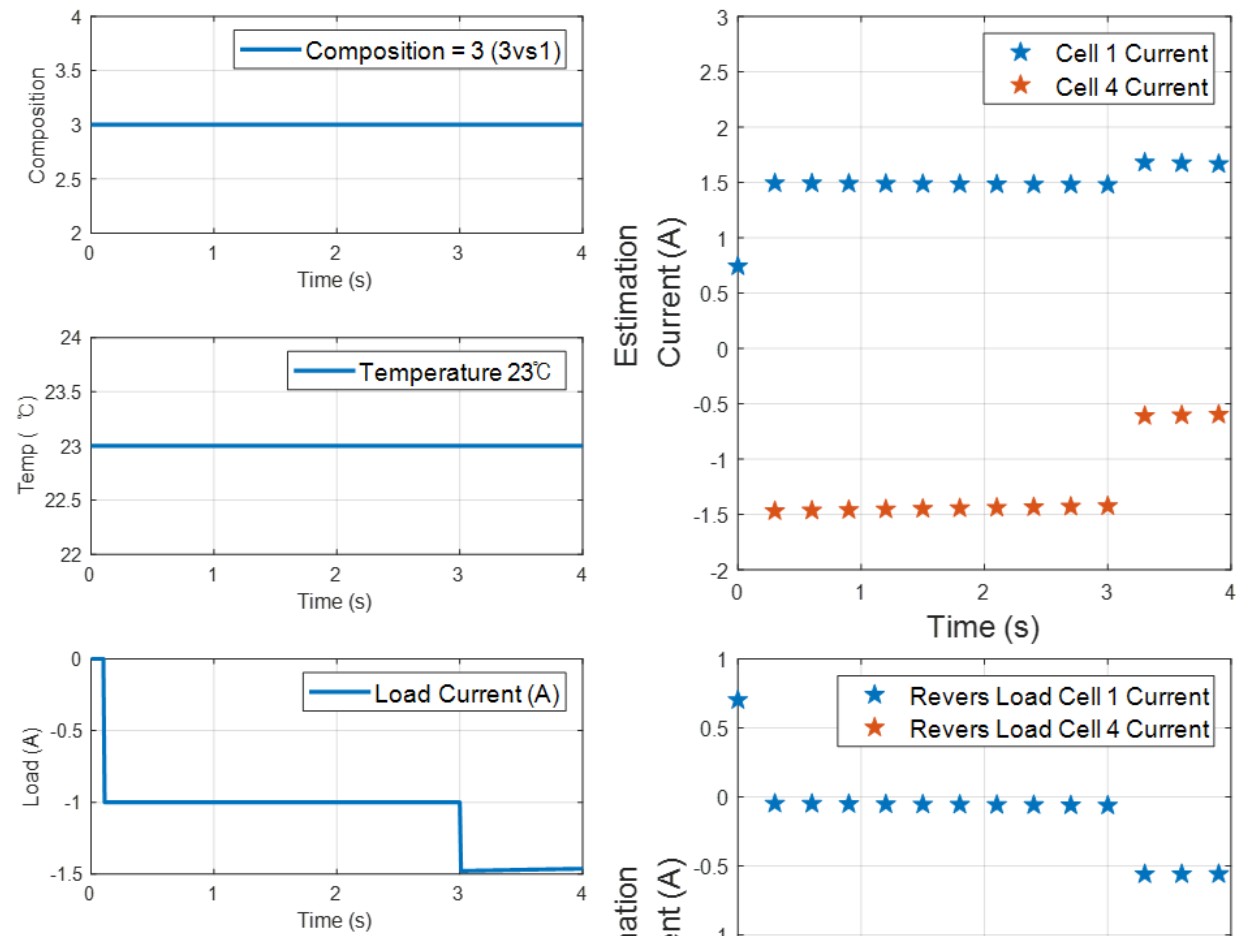

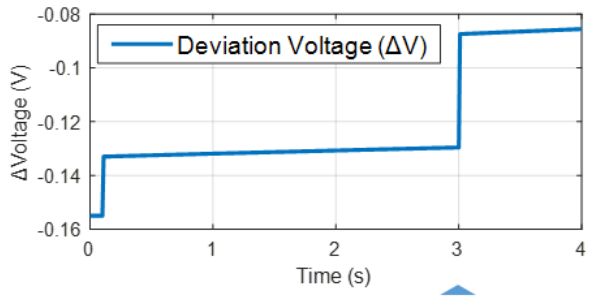

(a)

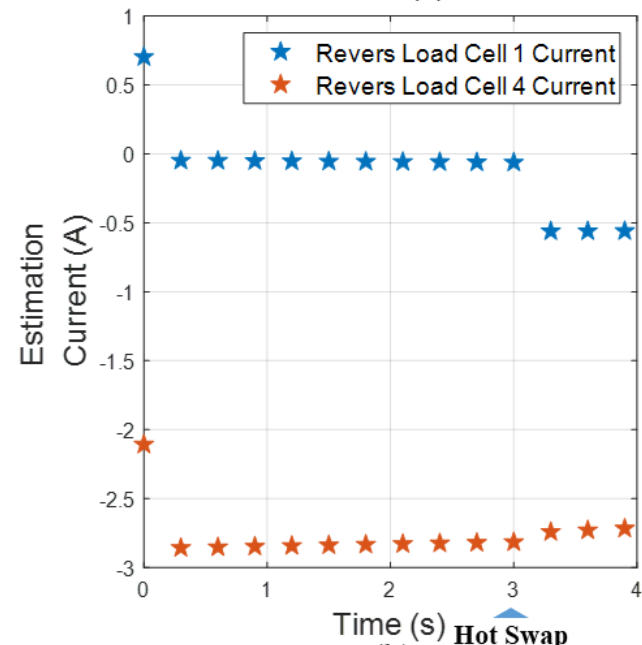

(b)

Figure 16. Verification of the results obtained for the hot-swap circulating current with the ANN model. (a) ANN input data, (b) ANN Estimation Circulation Current. 
Table 8. Comparison of ANN model with simulation results.

\begin{tabular}{ccccccccc}
\hline \multirow{2}{*}{ Load } & \multicolumn{2}{c}{ Cell_1 } & \multicolumn{3}{c}{ Reverse Load } & \multicolumn{2}{c}{ Load } & \multicolumn{2}{c}{ Cell_4 (New) } \\
\hline Simul & ANN & Simul & ANN & Simul & ANN & Simul & ANN \\
\hline $1.435 \mathrm{~A}$ & $1.425 \mathrm{~A}$ & $-1.47 \mathrm{~A}$ & $-1.47 \mathrm{~A}$ & $0.065 \mathrm{~A}$ & $0.063 \mathrm{~A}$ & $2.801 \mathrm{~A}$ & $2.815 \mathrm{~A}$ \\
\hline
\end{tabular}

\subsubsection{Experiment-Based ANN Model Validation}

Figure 17 shows the experimental results in which cell 2 and cell 3 are sequentially hot-swapped at $10 \mathrm{~s}$ intervals while battery cell 1 is connected to the DC bus in a 1S4P battery pack. At this time, the magnitude of the circulating current estimated in the ANN model is shown together with a circle.
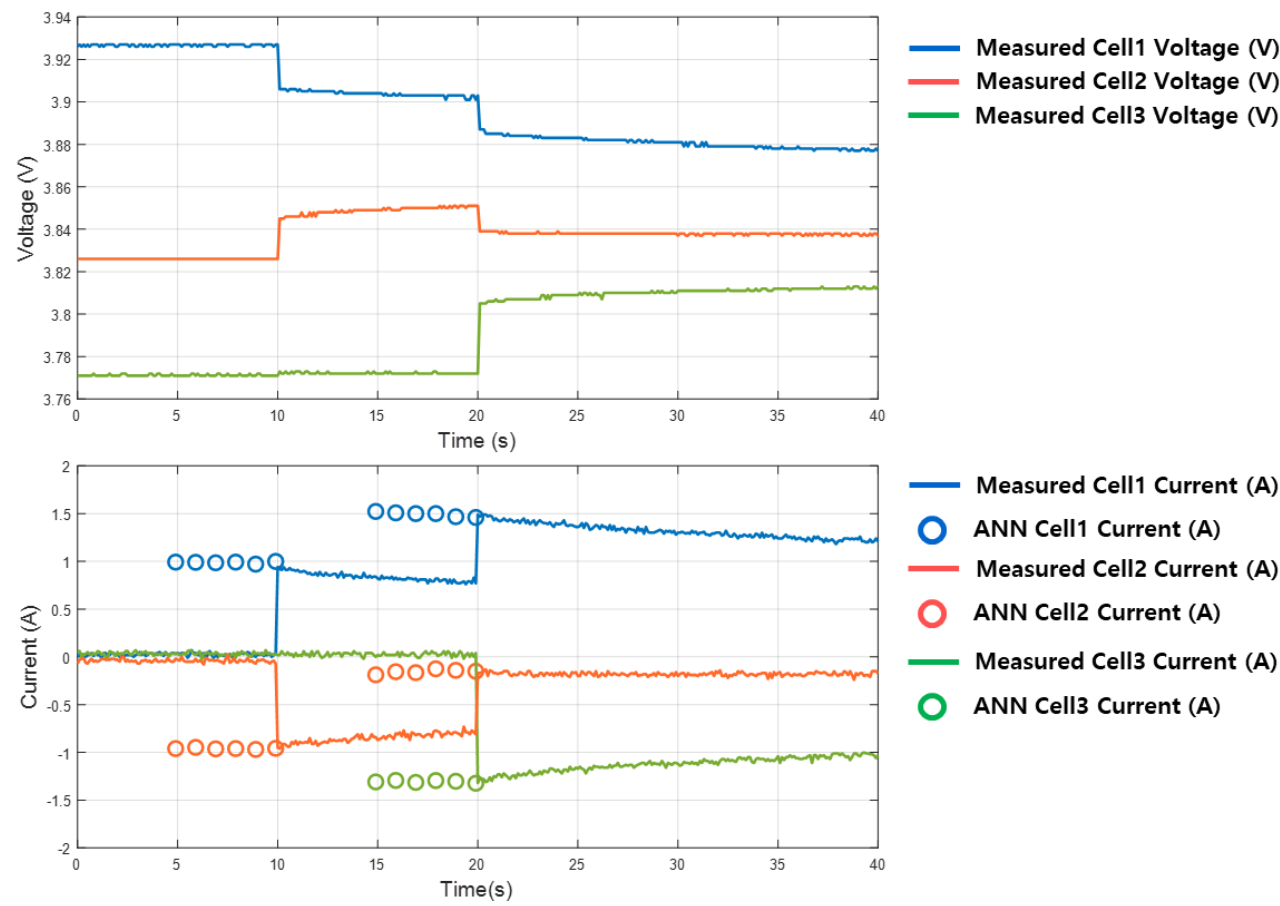

Figure 17. Experimental result of hot swap operation of three batteries with voltage deviation and simulation result of estimated circulating current of ANN model.

As a result of the 1 vs. 1 hot swap with a voltage difference of $0.101 \mathrm{~V}$ at the time of $10 \mathrm{~s}$, it was experimentally measured that the discharge current of $0.94 \mathrm{~A}$ in cell 1 and the charging current of $-0.95 \mathrm{~A}$ in cell 2 occurred. At this time, it can be seen that the ANN model estimates that the circulating current is $0.99 \mathrm{~A}$ for cell 1 and $-0.96 \mathrm{~A}$ for cell 2, and the current generated during the hot swap is estimated to be within $\pm 0.05 \mathrm{~A}$. At the time point of $20 \mathrm{~s}$, cell 3 is hot swapped while cell 1 and cell 2 are connected. From the experimental results, it can be seen that the peak values of the circulating currents of cells 1,2 , and 3 are $1.49 \mathrm{~A},-0.17 \mathrm{~A}$, and $-1.32 \mathrm{~A}$. Under the same experimental conditions, cell 1,2 , and 3 currents, estimated using the ANN model, are $1.495 \mathrm{~A},-0.15 \mathrm{~A}$, and $-1.32 \mathrm{~A}$, which are indicated by circles in Figure 17. Table 9 summarizes the magnitude of the peak current generated during the hot swap from the above experiment and simulation results. As shown in Table 9, it can be confirmed that the peak value of the circulating current that occurs when the cell to be hot-swapped is connected to the DC bus can be estimated with the ANN model proposed in this paper. 
Table 9. Comparison of peak current estimation results and experimental results during hot swap.

\begin{tabular}{ccccccccc}
\hline \multicolumn{2}{c}{ Cell_1 } & \multicolumn{2}{c}{ 10 s } & \multicolumn{2}{c}{ Cell_2 (New) } & \multicolumn{2}{c}{ Cell_1 } & \multicolumn{2}{c}{ Cell_3 (New) } \\
\hline Measured & ANN & Measured & ANN & Measured & ANN & Measured & ANN \\
\hline 0.94 A & 0.99 A & $-0.95 \mathrm{~A}$ & $-0.96 \mathrm{~A}$ & $1.49 \mathrm{~A}$ & $1.495 \mathrm{~A}$ & $-1.32 \mathrm{~A}$ & $-1.38 \mathrm{~A}$ \\
\hline
\end{tabular}

\title{
5. Conclusions
}

In this study, a method for estimating the circulating current generated during the hot-swap operation applied to multiple series and multiple parallel battery systems using the ANN model was proposed. The circulating current generated during the hot swap is determined not only by simple differences in the state of charge, but also by complex relationships, such as the parallel configuration of multiple parallel systems, temperature and load current. Therefore, it is difficult to calculate and estimate the circulating current considering various conditions. In this study, the multi-simulation results used in the hotswap analysis to build an artificial neural network (ANN) model can be used to estimate circulation currents for training battery configuration, temperature, load current, and power deviation conditions. For performance validation of the ANN model reflecting the above four conditions (parallel configuration, temperature, current, i.e., deviation), when compared with the hot-swap simulation results, the circulation current estimate was found to be around $97 \%$. We also performed periodic current estimation for approximately $94 \%$ of the ANN model performance for the 1S4P battery pack.

The ANN model proposed in this study was validated in a 1s4p system with a small number of cells connected in parallel. Therefore, in addition to this study, it is necessary to design an ANN estimation model for a battery system with more series and parallel connections to verify its estimation performance. In addition, it is necessary to study the algorithm to increase the safety and efficiency of the multi-parallel battery system by applying the estimated circulating current estimation result to the power management algorithm.

Author Contributions: N.-G.L. contributed to the main ideas of this study and wrote the paper. J.-Y.K. and S.L. comprehensively revised the paper. All authors approved the final version of the manuscript for publication. All authors have read and agreed to the published version of the manuscript.

Funding: This study was supported by the Korea Institute for Advancement of Technology (KIAT) grant funded by the Korean Government (MOTIE) (P0002092, The Competency Development Program for Industry Specialist). This work was supported by the National Research Foundation of Korea (NRF) grant funded by the Korea government (MSIT) (No. NRF-2021R1F1A1063150).

Conflicts of Interest: The authors declare no conflict of interest.

\author{
Abbreviations \\ SOC State of Charge \\ $\mathrm{SOH}$ State of Health \\ ECM Equivalent Circuit Model \\ BMS Battery Management System \\ EV Electric Vehicles \\ ESS Energy Storage System \\ ANN Artificial Neural Network \\ Fitnet Fitting Network \\ MSE Mean Square error \\ MAE Mean Absolute error \\ LUT Look up Table \\ OCV Open Circuit Voltage
}




\section{References}

1. Gabar, H.A.; Othman, A.M.; Abdussami, M.R. Review of Battery Management Systems(BMS) Development and Industrial Standards. Technologies 2021, 9, 28. [CrossRef]

2. Lelie, M.; Braun, T.; Knips, M.; Nordmann, H.; Ringbeck, F.; Zappen, H.; Sauer, D.U. Battery Management System Hardware Concepts: An Overview. Appl. Sci. 2018, 8, 534. [CrossRef]

3. Luo, X.; Kang, L.; Lu, C.; Linghu, J.; Lin, H.; Hu, B. An Ehanced Multicell-to-Multicell Battery Equalizer Based on BipolarReseonant LC Converter. Electronics 2021, 10, 293. [CrossRef]

4. Aiello, O. Electromagnetic Susceptibility of Battery Management Systems' ICs for Electric Vehicles: Experimental Study. Electronics 2020, 9, 510. [CrossRef]

5. Doridant, A.; Abouda, K.; Givelin, P.; Thibaud, B. Battery Management System Demonstrator Board design using EMC System simulation. In Proceedings of the 2019 International Symposium on Electromagnetic Compatibility-EMC EUROPE, Barcelona, Spain, 2-6 September 2019; pp. 427-432.

6. Wei, Z.; Zhao, J.; He, H.; Ding, G.; Cui, H.; Liu, L. Future smart battery and management: Advanced sensing from external to embedded multi-dimensional measurement. J. Power Sources 2021. [CrossRef]

7. Baronti, F. Investigation of series-parallel connections of multi-module batteries for electrified vehicles. In Proceedings of the IEEE International Electric Vehicle (IEVC) (2014), Florence, Italy, 17-19 December 2014; pp. 1-7.

8. Jiang, Y.; Habib, A.H.; Zhao, X.; Shrinkle, L.J.; Callafon, R. Centralized recursive optimal scheduling of parallel buck regulated battery modules. Proceedings of IEEE Conference on Decision and Control (CDC) (2017), Melbourne, VIC, Australia, 12-15 December 2017; pp. 2029-2034.

9. Moo, C.-S.; Ng, K.S.; Hsieh, Y.-C. Parallel Operation of Battery Power Modules. IEEE Trans. Energy Convers. 2008, $23,701-707$.

10. Hsu, C.T.; Sheng, S.; Sun, Q.; Li, P.; Lehman, B. Increased energy delivery for parallel battery packs with no regulated bus. In Proceedings of the Intelec 2012, Scottsdale, AZ, USA, 30 September-4 October 2012; pp. 1-8.

11. Song, C.; Shao, Y.; Song, S.; Chang, C.; Zhou, F.; Peng, S.; Xiao, F. Energy management of parallel-connected cells in electric vehicles based on fuzzy logic control. Energies 2017, 10, 404. [CrossRef]

12. Lee, S.; Kim, J. Inrush current estimation and hot-swapping for safe parallel battery pack. Int. J. Electron. 2020, 107, 1609-1624. [CrossRef]

13. Lee, S.; Kim, J.; Ha, M.; Song, H. Inrush current estimation for hot swap of the parallel connected large capacity battery pack. Proceedings of IEEE Energy Conversion Congress and Exposition (ECCE) (2018), Portland, OR, USA, 23-27 September 2018; pp. 2489-2492.

14. Chou, C.J.; Jiang, S.B.; Yeh, T.L.; Sun, C.C. Fault-Tolerant Battery Power Network Architecture of Networked Swappable Battery Pack in Parallel. Energy 2012, 14, 2841.

15. Lin, H.-T.; Liang, T.-J.; Chen, S.-M. Estimation of Battery State of Health Using Probabilistic Neural Network. IEEE Trans. Ind. Inform. 2013, 9, 679-685. [CrossRef]

16. Mahmoud, I.; Rioch, D.; Ahmed, E.; Ryan, A.; Saeid, H. Battery state of charge estimation using an Artificial Neural Network. In Proceedings of the 2017 IEEE Transportation Electrification Conference and Expo (ITEC) (2017), Chicago, IL, USA, 22-24 June 2017; pp. 342-349.

17. Farmann, A.; Waag, W.; Marongiu, A.; Sauer, D.U. Critical review of on-board capacity estimation techniques for lithium-ion batteries in electric and hybrid electric vehicles. J. Power Sources 2015, 281, 114-130. [CrossRef]

18. Zhu, Q.; Xu, M.; Liu, W.; Zheng, M. A state of charge estimation method for lithium-ion batteries based on fractional order adaptive extended kalman filter. Energy 2019, 187, 115880. [CrossRef]

19. Ismail, M. Estimation Strategies for Training of Deep Learning Neural Networks. Ph.D. Thesis, McMaster University, Hamilton, ON, USA, 2018.

20. Math Works Deep Learning Tool Box. Neural Network Patternnet. Available online: https://mathworks.com/products/deeplearning.html\#net (accessed on 16 June 2021).

21. Romero, A.; Ballas, N.; Kahou, S.E.; Chassang, A.; Gatta, C.; Bengio, Y. Fitnets: Hints for thin deep nets. arXiv 2014, arXiv:1412.6550.

22. Hemavathi, S. Overview of Cell Balancing Method for Li-ion Battery Technology. Energy Storage 2020, $203,1-12$.

23. Hu, J.; He, H.; Wei, Z.; Li, Y. Disturbance-Immune and Aging-Robust Internal Short Circuit Diagnostic for Lithium-Ion Battery, IEEE Trans. Ind. Electron. 2021. [CrossRef]

24. Wei, Z.; He, H.; Pou, J.; Tsui, K.L.; Quan, Z.; Li, Y. Signal-Disturbance Interfacing Elimination for Unbiased Model Parameter Identification of Lithium-Ion Battery. IEEE Trans. Ind. Inform. 2020. [CrossRef]

25. Wei, Z.G.; Hu, J.; He, H.; Li, Y.; Xiong, B. Load Current and State of Charge Co-Estimation for Current Sensor-Free Lithium-ion Battery. IEEE Trans. Power Electron. 2021. [CrossRef]

26. Westerhoff, U.; Kurbach, K.; Lienesch, F.; Kurrat, M. Analysis of Lithium-Ion Battery Models Based on Electrochemical Impedance Spectroscopy. Energy Technol. 2016, 4, 1620-1630. [CrossRef]

27. Robyn, J.; Michael, S.; Pravesh, S.; Javier, G.; Tarun, H.; Massimo, C. SAE Technical Paper Series-Battery Model Parameter Estimation Using a Layered Technique: An Example Using a Lithium Iron Phosphate Cell. In Proceedings of the SAE International SAE 2013 World Congress \& Exhibition, Detroit, MI, USA, 16-18 April 2013; pp. 1-14. 
28. Zhang, L.; Peng, H.; Ning, Z.; Mu, Z.; Sun, C. Comparative Research on RC Equivalent Circuit Models for Lithium-Ion Batteries of Electric Vehicles. Appl. Sci. 2017, 7, 1002. [CrossRef]

29. Renault Nissan Technology \& Business Centre India Private Limited, “Battery Parameter Estimation". Available online: https:/ / www.mathworks.com/content/dam/mathworks/mathworks-dot-com/images/events/matlabexpo/in/2018 /lithium-ion-battery-parameter-estimation-for-hil-sil-and-mil-validation.pdf/ (accessed on 19 April 2018).

30. Hagan, M.T.; Menhaj, M.B. Training feedforward networks with the Marquardt algorithm. IEEE Trans. Neural Netw. 1994, 5 , 989-993. [CrossRef] [PubMed] 